\title{
Predicting Recurrence after Chronic Subdural Haematoma Drainage
}

\author{
Andrew Jack, Cian O’Kelly, Cameron McDougall, J. Max Findlay
}

\begin{abstract}
Background: Recurrence of chronic subdural haematomas (CSDHs) after surgical drainage is a significant problem with rates up to $20 \%$. This study focuses on determining factors predictive of haematoma recurrence and presents a scoring system stratifying recurrence risk for individual patients. Methods: Between the years 2005 and 2009, 331 consecutive patients with CSDHs treated with surgery were included in this study. Univariate and multivariate analyses were performed searching for risk factors of increased postoperative haematoma volume and haematoma recurrence requiring repeat drainage. Results: We found a $12 \%$ reoperation rate. CSDH septation (seen on computed tomogram scan) was found to be an independent risk factor for recurrence requiring reoperation $(\mathrm{p}=0.04)$. Larger post-operative subdural haematoma volume was also significantly associated with requiring a second drainage procedure $(\mathrm{p}<0.001)$. Independent risk factors of larger post-operative haematoma volume included septations within a CSDH $(\mathrm{p}<0.01)$, increased pre-operative haematoma volume $(\mathrm{p}<0.01)$, and a greater amount of parenchymal atrophy $(\mathrm{p}=0.04)$. A simple scoring system for quantifying recurrence risk was created and validated based on patient age ( $<$ or $\geq 80$ years), haematoma volume $(<$ or $\geq 160 \mathrm{cc})$, and presence of septations within the subdural collection (yes or no). Conclusion: Septations within CSDHs are associated with larger postoperative residual haematoma collections requiring repeat drainage. When septations are clearly visible within a CSDH, craniotomy might be more suitable as a primary procedure as it allows greater access to a septated subdural collection. Our proposed scoring system combining haematoma volume, age, and presence of septations might be useful in identifying patients at higher risk for recurrence.
\end{abstract}

RÉSUMÉ: Prédiction d'une récidive après drainage d'un hématome sous-dural chronique. Contexte: La récidive d'hématomes sous-duraux chroniques (HSDC) après drainage chirurgical est un problème important dont le taux peut s'élever jusqu'à 20\%. Cette étude cible les facteurs de prédiction déterminants d'une récidive et présente un système d'évaluation stratifiant le risque de récidive pour des patients particuliers. Méthode: Trois cent trente et un patients consécutifs atteints d'un HSDC, qui ont subi une chirurgie entre 2005 et 2009, ont été inclus dans l'étude. Les données ont fait l'objet d'analyses univariées et multivariées pour rechercher les facteurs de risque d'une augmentation du volume de l'hématome après la chirurgie et d'une récidive de l'hématome nécessitant un nouveau drainage. Résultats: Le taux de réintervention chez nos patients était de 12\%. Le cloisonnement de l'HSDC (tel que visualisé à la tomodensitométrie) s'est avéré un facteur de risque indépendant de récidive nécessitant une réintervention $(\mathrm{p}=0,04)$. Un hématome sous-dural plus considérable en post-opératoire était également associé significativement avec la nécessité d'un second drainage ( $\mathrm{p}<0,01)$. Les facteurs de risque d'un hématome plus considérable après la chirurgie étaient le cloisonnement à l'intérieur de l'HSDC (p $<0,01)$, une augmentation du volume de l'hématome avant la chirurgie $(\mathrm{p}<0,01)$ et une atrophie parenchymateuse plus importante $(\mathrm{p}<0,04)$. Un système de notation simple basé sur l'âge du patient ( $<$ ou $\geq 80$ ans), le volume de l'hématome $(<$ ou $\geq 160 \mathrm{cc}$ ) et la présence de cloisons dans l'hématome (oui ou non) pour quantifier le risque de récidive a été créé et validé. Conclusion: Un cloisonnement dans l'HSDC est associé à un hématome résiduel plus considérable en post-opératoire nécessitant un nouveau drainage. Quand des cloisons sont clairement visibles à l'intérieur d'un HSDC, une craniotomie peut être plus appropriée comme première intervention parce qu'elle permet un meilleur accès à tous les segments de l'hématome. Le système de notation que nous proposons, qui combine le volume de l'hématome, l'âge et la présence de cloisonnement, pourrait être utile pour identifier les patients à plus haut risque de récidive.

Keywords: Chronic subdural hematoma, intracranial hemorrhage, multivariate analysis, recurrence, risk factor, scoring scale

doi:10.1017/cjn.2014.122

Can J Neurol Sci. 2015; 42: 34-39

Recurrence of chronic subdural haematomas $(\mathrm{CSDH})$ requiring reoperation occurs in up to $20 \%$ of patients. ${ }^{1-9}$ Numerous risk factors for both occurrence and recurrence of $\mathrm{CSDH}$ have been proposed. ${ }^{1,10-17}$ Despite efforts to identify and understand risk factors, the recurrence rate of $\mathrm{CSDHs}$ has remained relatively constant over the past few decades. ${ }^{1,9-12,16-18}$ In this study we evaluated clinical, operative, and radiological factors influencing haematoma recurrence in 331 consecutive cases of CSDHs in patients who underwent surgical drainage in our center.
We propose a scoring system based on demographic and radiological features to identify patients at highest risk for $\mathrm{CSDH}$ recurrence.

From the Division of Neurosurgery, Department of Surgery, University of Alberta, Edmonton, Alberta, Canada

Received July 8, 2014. Final Revisions Submitted November 23, 2014. Correspondence to: Andrew Jack, Division of Neurosurgery, Department of Surgery, University of Alberta, Edmonton, Alberta, T6E-0X7, Canada. E-mail: asjack@ualberta.ca 


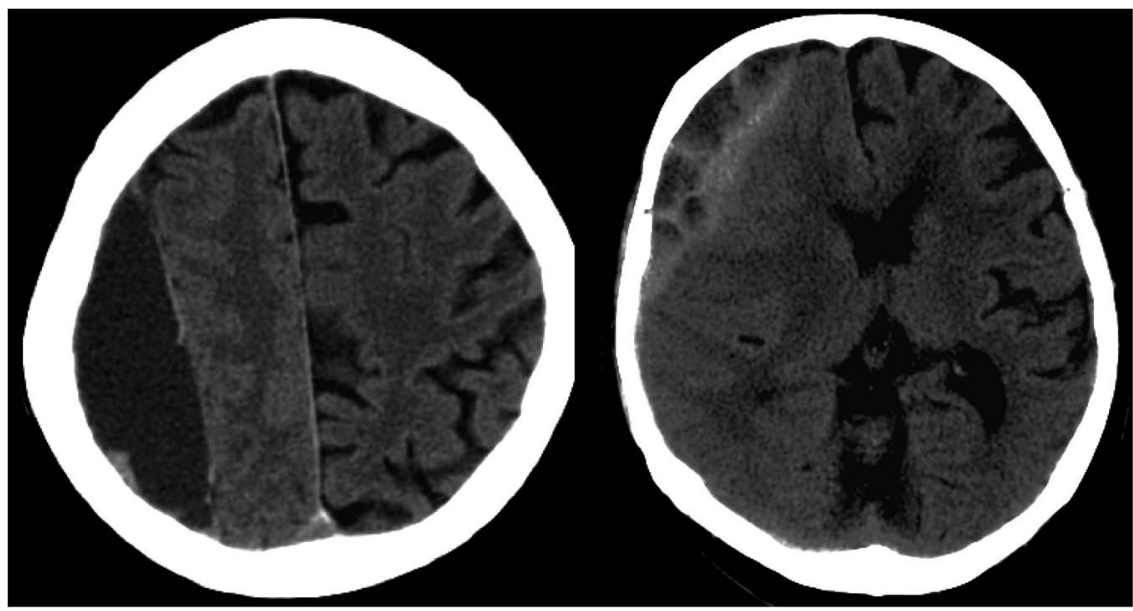

Figure 1: Typical CT appearance of a CSDH without visible septations (left) and with septations (right).

\section{Methods}

Ethics approval for this study was obtained from the local institutional Healthcare Research Ethics Board. A retrospective review of 308 consecutive patients between January 2005 and December 2009 was completed, and yielded a total of 331 CSDHs that underwent drainage by 10 treating surgeons. At our institution all CSDHs are drained in an operating room with a catheter attached to a closed drain system for slow, continuous drainage post-operatively. As such, all patients were identified from operative records. Clinical and demographic information was collected via an electronic medical record, including patient age, gender, and use of anticoagulants. Prior to surgery all patients had their coagulation status normalized. Patient use of antiplatelet agents was not investigated. Factors related to operative technique were collected including the type of procedure (burr-hole or craniotomy), both initially and upon recurrence, and the number of recurrences. The picture archive and communication system (PACS) was used to gather pre-operative and post-operative radiological data from computed tomogram (CT) scans of the head for each case including: haematoma volume (calculated by the $\mathrm{ABC} / 2$ method previously described for $\mathrm{CSDHs}^{19-21}$ ), midline shift, parenchymal atrophy (assessed based on a three-grade system previously described ${ }^{17,18}$ ), location (left or right hemisphere), CSDH subtype (hypodense, isodense, hyperdense or mixed as previously described ${ }^{1,17,18,22}$ ), and the presence of internal haematoma septations as described in previous reports. ${ }^{1,2}$ Intra-haematoma septations were defined as visible membranes on CT within the haematoma cavity, separating it into distinct compartments as shown in Figure 1.

Recurrence was defined as the re-accumulation of CSDH requiring drainage within three months of the initial procedure (approximate time-frame allowing at least one clinical follow-up visit and subsequent re-drainage). All patients had a routine early post-operative CT head, and as such radiological data was collected within a few days of surgery. Each variable was subject to univariate analysis using Statistical Analysis System computer software (version 9.2; SAS, Cary, North Carolina) and subsequently used for multivariate analysis using a logistical regression model in order to identify independent risk factors. Chi squared was used for determining the relationship between CSDH recurrence and categorical variables. A t-test was used for continuous variables, and analysis of variance (ANOVA) testing for continuous subgroup variables with logistical regression modeling.

The results of the analysis for each factor and its relation to CSDH recurrence were calculated as an odds ratio and $95 \%$ confidence interval. Statistical significance was set at a p-value of less than 0.05 . Risk factors related to haematoma recurrence were used in a statistical selection test in order to identify and create the best model for a scoring system based on high-risk patient groups for recurrence. High-risk groups and threshold values for risk factors used in the scoring system (pre-operative haematoma volume $<$ or $\geq 160 \mathrm{cc}$, patient age $<$ or $\geq 80$ years, and presence of intra-haematoma septations) were identified based on the $75^{\text {th }}$ percentile of recurrence for each factor. The scoring system to predict CSDH recurrence was then applied to our patient database for internal validation.

\section{Results}

The baseline clinical, technical and radiological characteristics are outlined in Table 1. The overall reoperation rate was $11.8 \%$ (39 operations). The majority of patients underwent burrhole drainage (89.4\%) as opposed to craniotomy for drainage $(10.6 \%)$ of their CSDH. Fifteen patients (15/39) underwent repeat burr-hole drainage and 24 patients (24/39) underwent a craniotomy as the second procedure for CSDH drainage. Four patients required an additional third operation for CSDH recurrence, two of which were repeat craniotomies as shown in Table 2.

Univariate and multivariate analysis results of the relationship between post-operative residual haematoma volume and each risk factor are shown in Table 3. Multivariate analysis demonstrated that increased pre-operative haematoma volume $(\mathrm{p}<0.01)$, a greater amount of parenchymal atrophy $(p=0.04)$, and presence of septations $(\mathrm{p}<0.01)$ all to be statistically significant predictors for increased post-operative haematoma volume.

Data from patients with CSDH recurrence requiring reoperation is presented in Table 4. Upon multivariate analysis, the 
Table 1: Baseline clinical, technical, and radiological characteristics from patients with 331 chronic subdural haematomas

\begin{tabular}{|c|c|}
\hline Factor & Number of Patients (\%) \\
\hline \multicolumn{2}{|l|}{ Gender } \\
\hline Male & $267(80.7)$ \\
\hline Female & $64(19.3)$ \\
\hline \multicolumn{2}{|l|}{ Mean Age (years) } \\
\hline Male & $69.1 \pm 14.3$ \\
\hline Female & $69.4 \pm 14.0$ \\
\hline \multicolumn{2}{|l|}{ Anticoagulated } \\
\hline Yes & $51(15.4)$ \\
\hline No & $280(84.6)$ \\
\hline \multicolumn{2}{|l|}{ CT Hematoma Density } \\
\hline Hypodense & $34(10.3)$ \\
\hline Isodense & $48(14.6)$ \\
\hline Hyperdense & $10(3.0)$ \\
\hline Mixed & $238(72.1)$ \\
\hline \multicolumn{2}{|l|}{ Septated } \\
\hline Yes & $244(79.3)$ \\
\hline No & $86(20.7)$ \\
\hline Mean Midline Shift (mm) & $7.2 \pm 5.2$ \\
\hline \multicolumn{2}{|l|}{ Brain Atrophy } \\
\hline No or Mild Atrophy & $77(23.3)$ \\
\hline Definite Atrophy & $146(44.1)$ \\
\hline Severe Atrophy & $108(32.6)$ \\
\hline Mean Pre-Operative Volume (cc) & $130.4 \pm 56.2$ \\
\hline \multicolumn{2}{|l|}{ Hemisphere } \\
\hline Left & $171(51.7)$ \\
\hline Right & $160(48.3)$ \\
\hline
\end{tabular}

$\mathrm{CT}=$ computed tomogram

Table 2: Frequency of chronic subdural haematoma recurrence

\begin{tabular}{l|c}
\hline Number of recurrences & Number of CSDHs (\%) \\
\hline 1 & $35(89.7)$ \\
\hline 2 & $4(10.3)$ \\
\hline Total & $39(11.8)$ \\
\hline
\end{tabular}

$\mathrm{CSDH}=$ chronic subdural haematoma

presence of $\mathrm{CSDH}$ septations pre-operatively $(\mathrm{p}=0.04)$ was found to be a predictor for requiring a second operation for CSDH drainage. Patients with larger residual haematomas following their initial surgical drainage were also more likely to require a second operation for re-drainage of a haematoma $(\mathrm{p}<0.01)$.

A scoring system predicting $\mathrm{CSDH}$ recurrence was created using statistical selection methods, as shown in Table 5 and Figure 2. Patients at highest risk for reoperation were stratified based on age ( $<$ or $\geq 80$ years), pre-operative haematoma volume
Table 3: Univariate and multivariate analysis results of factors related to increased post-operative residual haematoma volume

\begin{tabular}{l|c|c}
\hline Factor & $\begin{array}{c}\text { Univariate Analysis } \\
\text { (P-Value) }\end{array}$ & $\begin{array}{c}\text { Multivariate Analysis } \\
\text { (P-Value) }\end{array}$ \\
\hline Age & $<0.01$ & 0.41 \\
\hline CT Haematoma Density & 0.50 & 0.42 \\
\hline Septations & $<0.01$ & 0.01 \\
\hline Midline Shift & $<0.01$ & 0.99 \\
\hline Atrophy & $<0.01$ & 0.04 \\
\hline $\begin{array}{l}\text { Pre-operative Haematoma } \\
\text { Volume }\end{array}$ & $<0.01$ & $<0.01$ \\
\hline CT = computed tomography &
\end{tabular}

Table 4: Univariate and multivariate analysis results of factors related to haematoma recurrence requiring repeat drainage

\begin{tabular}{l|c|c}
\hline Factor & $\begin{array}{c}\text { Univariate Analysis } \\
\text { (P-Value) }\end{array}$ & $\begin{array}{c}\text { Multivariate Analysis } \\
\text { (P-Value) }\end{array}$ \\
\hline Gender & 0.07 & 0.08 \\
\hline Age & 0.95 & 0.91 \\
\hline $\begin{array}{l}\text { CT Hematoma } \\
\text { Density }\end{array}$ & 0.68 & 0.39 \\
\hline Loculations & $<0.01$ & 0.04 \\
\hline Midline Shift & $<0.01$ & 0.07 \\
\hline Atrophy & 0.76 & 0.78 \\
\hline $\begin{array}{c}\text { Pre-Operative } \\
\text { Volume }\end{array}$ & $<0.01$ & 0.29 \\
\hline $\begin{array}{l}\text { Operative Procedure } \\
\text { (Burr-Hole) }\end{array}$ & 0.04 & 0.24 \\
\hline CT computed tomography con &
\end{tabular}

Table 5: Risk factor scoring system for chronic subdural haematoma recurrence requiring repeat surgical drainage

\begin{tabular}{l|c}
\hline Risk Factor & Score \\
\hline Age (years) & \\
\hline$\leq 80$ & 0 \\
\hline$>80$ & 1 \\
\hline CSDH Volume (cc) & \\
\hline$\leq 160$ & 0 \\
\hline$>160$ & 1 \\
\hline Haematoma Septations & \\
\hline Absent & 0 \\
\hline Present & 1 \\
\hline
\end{tabular}

CSDH - chronic subdural haematoma; $\mathrm{cc}=$ cubic centimeters

( $<$ or $\geq 160 \mathrm{cc}$ ) and presence of septations on pre-operative CT (yes or no). For each risk factor identified, an additional point is added to the total score (for example, a patient who is $\geq 80$-years-old, has a haematoma volume $\geq 160 \mathrm{cc}$, and has a septated CSDH on CT would be attributed a total score of 3). This scoring system was found to be strongly associated with 


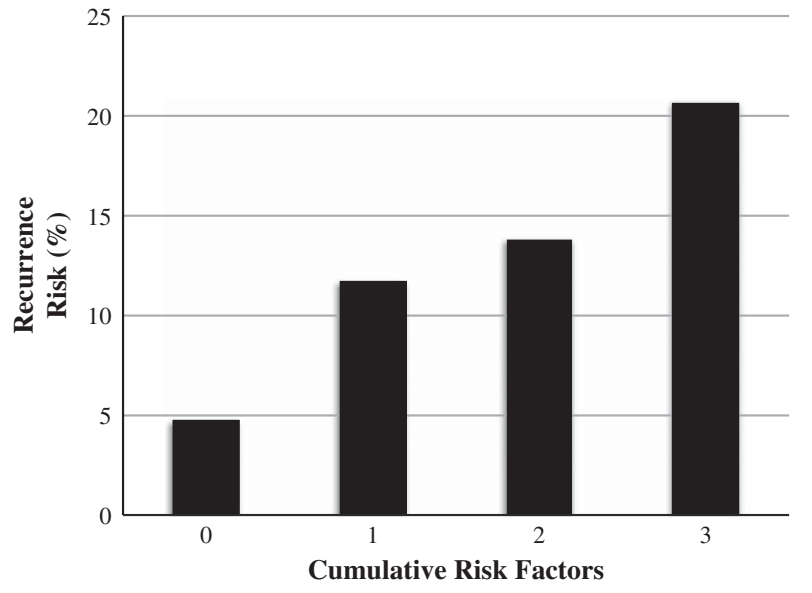

Figure 2: Patient CSDH recurrence risk based on their cumulative risk factor score.

predicting post-operative residual haematoma volume. There was also a significant trend for predicting reoperation $(\mathrm{p}=0.02)$ on chi-square testing. Based on this scoring system and our dataset, the rate of reoperation based on haematoma recurrence for patients was $4.8 \%, 11.7 \%, 13.8 \%$, and $20.7 \%$ for scores of $0,1,2$, and 3 , respectively (Figure 2).

\section{Discussion}

Several risk factors for CSDH recurrence have been previously reported, including: advanced age, bleeding tendency, alcohol abuse, brain atrophy, hematoma density, bilateral CSDHs, among others. $^{1,10-17,23-24}$ However, results identifying consistent risk factors have been difficult to reproduce. ${ }^{2,4,17,25}$ Through multivariate analysis and logistic regression we sought to identify risk factors for $\mathrm{CSDH}$ recurrence requiring repeat drainage and increased postoperative subdural haematoma volume. Outlined are the risk factors found to be associated with increased post-operative haematoma volume and $\mathrm{CSDH}$ recurrence requiring repeat drainage. A simple scoring system for predicting $\mathrm{CSDH}$ recurrence for patients is also proposed.

\section{Septations}

The presence of septations within a CSDH has been previously related to recurrence. ${ }^{2,22,26}$ However, separate statistical evaluation of septations within the clot has rarely been done. In the present study, the presence of septations was statistically significant for higher residual haematoma volume and $\mathrm{CSDH}$ recurrence requiring re-drainage. Septated haematomas are more difficult to drain as disruption of each compartment is necessary for complete drainage.

\section{Atrophy}

A greater amount of parenchymal atrophy was found on multivariate analysis to be a predictor of increased post-operative haematoma volume. It has been well described as being a risk factor for both occurrence and recurrence of CSDH. ${ }^{1,2,17,18,22,25}$ This has been explained by examining brain elastance. Higher elastance is associated with increasing age, atrophy and persistence of a subdural space. ${ }^{4,14,17,18}$

\section{Pre-operative Haematoma Volume}

Increased pre-operative haematoma volume was a significant predictor of higher post-operative residual haematoma volume. Larger CSDHs have a lower surface to volume ratio, which has been suggested to result in decreased absorption of the haematoma fluid once a particular threshold is passed. ${ }^{11}$ Larger haematomas are also more difficult to completely drain (particularly through a burr hole). As a result, incomplete drainage and less promotion of thrombosis and re-absorption may occur.

\section{Post-Operative Haematoma Volume}

Interestingly, increased post-operative haematoma volume was significantly associated with requiring a second drainage procedure. Within a CSDH there is a micro-environment of hyperfibrinolysis and hypercoagulation. ${ }^{2,17}$ Haematoma resolution is determined by the difference between re-absorption and microvascular leakage. ${ }^{16,27-31}$ If there is a larger residual haematoma, then the balance may not have been shifted beyond this therapeutic threshold.

\section{Scoring System}

The combination of increased pre-operative haematoma volume, advanced patient age, and the presence of intrahaematoma septations was found to have the greatest statistical influence on predicting increased residual haematoma volume and operative recurrence. By dichotomizing patients into high- and low-risk groups based on these variables, it was possible to quantify the increased risk of recurrence for patients from our database. For example, we found that patients with a score of ' 3 ' had a more than four-fold risk of recurrence compared to a patient with a score of ' 0 ' ( $\leq 80$-years-of-age, no septations, and haematoma volume $\leq 160 \mathrm{cc}$ ), and just under a two-fold risk compared to patients with a score of ' 1 '. This offers important prognostic information pre-operatively regarding an individual patient's risk of recurrence, as well as post-operatively with respect to following patients clinically and/or radiologically.

\section{Limitations}

This is a single-observer, retrospective study and, as such, is subject to bias. Despite a large patient cohort, a relatively lower rate of recurrence was found. Although it is ideal to have a recurrence rate as low as possible, this was also a limiting factor for identifying risk factors in our multivariate analysis model. Specifically, technical factors including the number of burr holes, lysis of subdural space septations, irrigation of the subdural space, the size of the craniostomy for drainage, amount of post-operative pneumocephalus, local or general anaesthetic use, among others, have been debated as affecting recurrence rates and neurological outcomes. ${ }^{2,4,17,18,22,32-36}$ In addition, although previous studies have found a difference in $\mathrm{CSDH}$ recurrence rates based on the initial procedure, here this was not found to be an independent risk factor upon multivariate analysis. However, it is possible that the number of patients in either cohort was not large enough to detect such as difference. Furthermore, the use of a drainage system has been previously shown to reduce recurrence and six-month mortality. ${ }^{32}$ Although it is routine practice at our institution to use a drain in CSDH drainage, other technical factors may have varied between treating surgeons affecting recurrence rate. For example, 
some surgeons will prefer to do a larger burr-hole or "mini-craniotomy" if septations are present, or prefer to use different types of craniostomy drills resulting in variable burr-hole sizes. Followup studies with the creation of a similar scoring system focusing more on clinical and technical factors such as those listed and less on radiological factors could prove useful. Moreover, patient use of antiplatelet agents was not accounted for. Increasing use of anti-platelet agents amongst patients is a potential limitation that should be accounted for in future studies. The creation of a scoring system for CSDH recurrence is novel, however further testing is required with larger sample sizes and/or recurrence rates from other datasets to validate this system. A larger sample size and/or higher recurrence rate may also allow for the inclusion of more factors. Application of this scoring system to prospectively collected datasets of clinical and radiological factors, in addition to its application to datasets collected from other institutions, is necessary for its validation.

\section{Conclusion}

Increased pre-operative haematoma volume, a greater amount of brain atrophy, and the presence of intra-haematoma septations were all risk factors on multivariate analysis for a larger postoperative haematoma collection. The presence of loculations and higher post-operative subdural haematoma volume were both predictors of CSDHs requiring reoperation. When septations are clearly visible within a CSDH on CT, craniotomy might be more suitable as a primary procedure as it allows more complete drainage of a septated subdural collection. A scoring model based on patient age, haematoma volume, and presence of intra-haematoma loculations may serve as a clinically useful way to help identify patients at risk for recurrence.

\section{Disclosures}

The authors of this paper have nothing to disclose.

\section{REFERENCES}

1. Nakaguchi H, Tanishima T, Yoshimasu N. Factors in the natural history of chronic subdural hematomas that influence their postoperative recurrence. J Neurosurg. 2001;95:256-62.

2. Yamamoto H, Hirashima Y, Hamada H, Hayashi N, Origasa H, Endo S. Independent predictors of recurrence of chronic subdural hematoma: results of multivariate analysis performed using a logistic regression model. J Neurosurg. 2003;98:1217-21.

3. Ramachandran R, Hegde T. Chronic subdural hematomas-causes of morbidity and mortality. Surg Neurol. 2007;67:367-72; discussion 72-3.

4. Mori K, Maeda M. Surgical treatment of chronic subdural hematoma in 500 consecutive cases: clinical characteristics, surgical outcome, complications, and recurrence rate. Neurol Med Chir. 2001;41:371-81.

5. Hamilton MG, Frizzell JB, Tranmer BI. Chronic subdural hematoma: the role for craniotomy reevaluated. Neurosurgery. 1993;33: 67-72.

6. Tsutsumi K, Maeda K, Iijima A, Usui M, Okada Y, Kirino T. The relationship of preoperative magnetic resonance imaging findings and closed system drainage in the recurrence of chronic subdural hematoma. J Neurosurg. 1997;87:870-5.

7. Mellergard P, Wisten O. Operations and re-operations for chronic subdural haematomas during a 25-year period in a well defined population. Acta Neurochir(Wien). 1996;138:708-13.

8. Matsumoto K, Akagi K, Abekura M, et al. Recurrence factors for chronic subdural hematomas after burr-hole craniostomy and closed system drainage. Neurol Res. 1999;21:277-80.
9. Ernestus RI, Beldzinski P, Lanfermann H, Klug N. Chronic subdural hematoma: surgical treatment and outcome in 104 patients. Surg Neurol. 1997;48:220-5.

10. Asano Y, Hasuo M, Takahashi I, Shimosawa S. [Recurrent cases of chronic subdural hematoma-its clinical review and serial CT findings]. No To Shinkei. 1992;44:827-31.

11. El-Kadi H, Miele VJ, Kaufman HH. Prognosis of chronic subdural hematomas. Neurosurg Clin N Am. 2000;11:553-67.

12. Foelholm R, Waltimo O. Epidemiology of chronic subdural haematoma. Acta neurochir (Wien). 1975;32:247-50.

13. Fogelholm R, Heiskanen O, Waltimo O. Chronic subdural hematoma in adults. Influence of patient's age on symptoms, signs, and thickness of hematoma. J Neurosurg. 1975;42:43-6.

14. Fukuhara T, Gotoh M, Asari S, Ohmoto T, Akioka T. The relationship between brain surface elastance and brain reexpansion after evacuation of chronic subdural hematoma. Surg Neurol. 1996;45:570-4.

15. Labadie EL, Glover D. Physiopathogenesis of subdural hematomas. Part 1: Histological and biochemical comparisons of subcutaneous hematoma in rats with subdural hematoma in man. J Neurosurg. 1976;45:382-92.

16. Markwalder TM. Chronic subdural hematomas: a review. J Neurosurg. 1981;54:637-45.

17. Oishi M, Toyama M, Tamatani S, Kitazawa T, Saito M. Clinical factors of recurrent chronic subdural hematoma. Neurol Med Chir (Tokyo). 2001;41:382-6.

18. Amirjamshidi A, Abouzari M, Eftekhar B, et al. Outcomes and recurrence rates in chronic subdural haematoma. Br J Neurosurg. 2007;21:272-5.

19. Gebel JM, Sila CA, Sloan MA, et al. Comparison of the ABC/2 estimation technique to computer-assisted volumetric analysis of intraparenchymal and subdural hematomas complicating the GUSTO-1 trial. Stroke. 1998;29:1799-801.

20. Kasner SE. Geometry and subdural hematoma volume. Stroke. 1999;30:188.

21. Sucu HK, Gokmen M, Gelal F. The value of XYZ/2 technique compared with computer-assisted volumetric analysis to estimate the volume of chronic subdural hematoma. Stroke. 2005;36:9981000 .

22. Stanisic M, Lund-Johansen M, Mahesparan R. Treatment of chronic subdural hematoma by burr-hole craniostomy in adults: influence of some factors on postoperative recurrence. Acta Neurochir. 2005;147:1249-56; discussion 56-7.

23. Krupp WF, Jans PJ. Treatment of chronic subdural haematoma with burr-hole craniostomy and closed drainage. $\mathrm{Br} \mathrm{J}$ Neurosurg. 1995;9:619-27.

24. Okada Y, Akai T, Okamoto K, Iida T, Takata H, Iizuka H. A comparative study of the treatment of chronic subdural hematomaburr hole drainage versus burr hole irrigation. Surg Neurol. 2002;57:405-9; discussion 10.

25. Torihashi K, Sadamasa N, Yoshida K, Narumi O, Chin M, Yamagata $\mathrm{S}$. Independent predictors for recurrence of chronic subdural hematoma: a review of 343 consecutive surgical cases. Neurosurgery. 2008;63:1125-9; discussion 9.

26. Tanikawa M, Mase M, Yamada K, et al. Surgical treatment of chronic subdural hematoma based on intrahematomal membrane structure on MRI. Acta Neurochir. 2001;143:613-8; discussion 8-9.

27. Ito $\mathrm{H}$, Komai $\mathrm{T}$, Yamamoto S. Fibrin and fibrinogen degradation products in chronic subdural hematoma. Neurologia Med Chir. 1975;15(pt 1):51-5.

28. Ito H, Komai T, Yamamoto S. Fibrinolytic enzyme in the lining walls of chronic subdural hematoma. J Neurosurg. 1978;48: 197-200.

29. Ito H, Yamamoto S, Komai T, Mizukoshi H. Role of local hyperfibrinolysis in the etiology of chronic subdural hematoma. J Neurosurg. 1976;45:26-31.

30. Markwalder TM, Steinsiepe KF, Rohner M, Reichenbach W, Markwalder $\mathrm{H}$. The course of chronic subdural hematomas after burr-hole craniostomy and closed-system drainage. J Neurosurg. 1981;55:390-6.

31. Weir B. The osmolality of subdural hematoma fluid. J Neurosurg. 1971;34:528-33. 
32. Santarius T, Kirkpatrick PJ, Ganesan D, et al. Use of drains versus no drains after burr-hole evacuation of chronic subdural haematoma: a randomised controlled trial. Lancet. 2009;374: 1067-1073.

33. Gelabert-Gonzalez M, Serramito-Garcia R. Chronic subdural hematoma: craniotomy versus burr hole trepanation. Br J Neurosurg. 2010;24:330, author reply 1.

34. Han HJ, Park CW, Kim EY, Yoo CJ, Kim YB, Kim WK. One vs. Two Burr Hole Craniostomy in Surgical Treatment of
Chronic Subdural Hematoma. J Korean Neurosurg Soc. 2009;46: 87-92.

35. Javadi A, Amirjamshidi A, Aran S, Hosseini SH. A randomized controlled trial comparing the outcome of burr-hole irrigation with and without drainage in the treatment of chronic subdural hematoma: a preliminary report. World Neurosurg. 2011;75:731-6; discussion 620-3.

36. Mondorf Y, Abu-Owaimer M, Gaab MR, Oertel JM. Chronic subdural hematoma-craniotomy versus burr hole trepanation. Br J Neurosurg. 2009;23:612-6. 